\title{
Impact of a fall prevention education program for health and exercise professionals: a randomised controlled trial
}

\author{
Anne Tiedemann a,f, Daina L Sturnieks ${ }^{b}$, Anne-Marie Hillc, \\ Lorraine Lovitt $^{\mathrm{d}}$, Lindy Clemsone ${ }^{\mathrm{e}}$, Stephen R Lord ${ }^{\mathrm{b}}$ and \\ Catherine Sherrington ${ }^{a}$ \\ a Institute for Musculoskeletal Health, University of Sydney and Sydney Local Health District, NSW, Australia \\ ${ }^{b}$ Neuroscience Research Australia, UNSW Sydney, Australia \\ c Faculty of Health Sciences, Curtin University, Perth, WA, Australia \\ d Clinical Excellence Commission, NSW Ministry of Health, Sydney, Australia \\ e School of Health Sciences, Faculty of Medicine and Health, University of Sydney, NSW, Australia \\ † Corresponding author: anne.tiedemann@sydney.edu.au
}

\section{Article history}

Publication date: October 2020

Citation: Tiedemann A, Sturnieks DL, Hill A-M, Lovitt L, Clemson L, Lord SR, Sherrington C. Impact of a fall prevention program for health and exercise professionals: a randomised controlled trial. Public Health Res Pract. 2020; Online early publication. https://doi.org/10.17061/ phrp30342013

\section{Key points}

- An education workshop for health and exercise professionals on exercise for fall prevention in older age improved knowledge, confidence and exercise prescription behaviour

- Workshop participants reported that they valued the mix of didactic and interactive teaching methods used

\section{Abstract}

Objectives and importance of study: Exercise prevents falls among community-dwelling older adults. Therefore, it is crucial that health and exercise professionals have the knowledge and skills to prescribe appropriate fall prevention exercise. This study evaluated the effect of a fall prevention education program, compared with a waitlist control group, on health and exercise professionals' fall prevention knowledge and behaviour, and their confidence to prescribe fall prevention exercises for older people.

Study type: Randomised controlled trial.

Methods: Participants were 200 health and exercise professionals recruited in New South Wales (NSW), Australia. The intervention group participated in a 1-day face-to-face education workshop on exercise to prevent falls in older age. The waitlist control group received the education intervention after completion of the 3-month follow-up. Primary outcomes were self-reported fall prevention knowledge, and change in prescribing behaviour for fall prevention exercise. Secondary outcomes were: confidence to prescribe fall prevention exercise; proportion of people aged 60 years and older seen in the past month who were prescribed fall prevention exercise; and proportion of fall prevention exercises prescribed in the past month that were evidence based. Data were analysed using analysis of covariance models for continuously scored outcomes and the differences in proportions between groups (relative risk $[R R]$ ).

Results: The intervention significantly improved knowledge (between-group difference [BGD] 0.27 points out of a possible $6 ; 95 \%$ confidence interval [CI] $0.03,0.51 ; p=0.03$ ), perceived clinical behaviour (RR 5.58; 95\% Cl 3.25, 9.59; $p<0.001$ ), confidence (BGD 1.02/10 points; 95\% Cl 0.65, 1.39; 
$p<0.001)$ and the proportion of evidence-based exercise prescribed, in both the number of exercises (BGD 0.36; 95\% Cl 0.03, 0.68; $p=0.03$ ) and percentage of participants who prescribed at least 2 hours/week of fall prevention exercise (RR 1.53; 95\% Cl 1.08, 2.15; $p=0.015)$.

Conclusion: The education workshop significantly improved participants' knowledge, confidence and behaviour regarding fall prevention exercise prescription.

\section{Introduction}

At least one-third of people aged 65 years and older fall once or more each year. ${ }^{1}$ Exercise prevents falls among older adults living in the community. The most effective programs include a high level of challenge for balance and a high dose of exercise. ${ }^{2}$ Health and exercise professionals are well placed to prescribe fall prevention exercise in their daily practice, if they have the appropriate knowledge and skills.

There is compelling evidence of the effectiveness of several approaches to improving health workers' clinical behaviour, including education workshops ${ }^{3}$, educational outreach visits involving face-to-face provision of information to change practice ${ }^{4}$ and audits of clinical care with feedback. ${ }^{5}$ A Cochrane review also found that the use of guidelines by health workers improves patient care. ${ }^{6}$ Educational meetings using a range of teaching and learning strategies can increase physiotherapists' use of clinical guidelines. ${ }^{7}$

Educational interventions have been extensively studied in some areas of healthcare, such as diabetes ${ }^{8}$ and infection control. ${ }^{9}$ However, in other areas, including fall prevention among community dwellers, there is a scarcity of research investigating staff behaviour change interventions. One trial that examined the effect of an educational intervention that aimed to encourage general practitioners to conduct medication reviews with older patients resulted in short-term reductions in the use of medications known to increase the risk of falling and an overall reduction in risk of falling in older patients after 12 months. ${ }^{10}$ We are unaware of any trials that have investigated interventions aimed at increasing health and exercise professionals' prescription of fall prevention exercise for older people, despite the clear evidence that exercise is effective in preventing falls. ${ }^{11}$

This trial aimed to evaluate the effect of a fall prevention education program on health and exercise professionals': 1) fall prevention knowledge; 2) fall prevention exercise prescription behaviour, and 3) confidence to prescribe fall prevention exercises, compared with a control group that was waitlisted to undertake the education program.

\section{Methods}

Participants were recruited between February 2015 and June 2016 in New South Wales (NSW), Australia, via advertising in newsletters and email lists of health professional organisations and special interest groups, such as the Australian Physiotherapy Association and NSW Falls Prevention Network, and through local health organisation managers. People were eligible for trial inclusion if they were a health or exercise professional whose clientele included people who were aged 60 years and older, and could commit to attending a free workshop on either of two dates as advised by the study team. Potential participants who were not fluent in written and spoken English were not eligible.

We conducted a parallel group randomised controlled trial, with follow-up 3 months post-randomisation. Participants were individually randomised to the intervention group or control group in equal numbers after baseline measurement of fall prevention knowledge, exercise prescription practice and confidence. To ensure allocation concealment, randomisation was undertaken by an investigator not involved in recruitment or assessment using a computer-generated randomisation schedule that was generated in advance, with randomly permuted block sizes of 2-6 and stratification by recruitment site.

The education workshop content was updated from a professional development program previously developed by the research team. ${ }^{12}$ It was delivered as a face-to-face 1-day workshop by experienced researchers for up to 35 attendees per session, using didactic and interactive teaching strategies, including formative feedback. Content covered falls epidemiology, risk factors and evidence-based interventions to prevent falls. ${ }^{2,13}$ The workshop also included active exercise and activity demonstrations, and participants working through exercise prescription scenarios. As the metaanalysis by Sherrington et al. ${ }^{2}$ found larger effects on falls from higher-dose exercise programs, and from exercise that provided a high level of challenge for balance, the workshop taught strategies to increase balance challenge and exercise dose. Participants were also directed to internet-based resources to assist with delivery of fall prevention exercise. The intervention content is published in detail ${ }^{14}$ and outlined in Appendix 1 (available from: hdl. handle.net/2123/19656).

Control group participants continued their usual practice and received the education workshop following the 3-month follow-up outcome reassessment. Outcomes were measured at baseline before randomisation and 
3 months after randomisation via self-report, trial-specific email or postal questionnaires.

\section{Primary outcome measures}

The two primary outcomes were:

- Fall prevention knowledge, assessed using six multiple choice questions about epidemiology of falls, risk factors, prevention strategies and fall prevention exercise, scored as total correct answers

- Change in fall prevention exercise prescription behaviour in the past 3 months. Participants answered two questions: "Do you think you have changed the way you prescribe fall prevention exercise in the past 3 months?" (measured with a 5-point Likert scale anchored at one end with "Yes, strongly agree" and at the other end with "No, strongly disagree"); and "If you strongly agree or agree to the question above, give at least one example of how you have changed the way you prescribed fall prevention exercise in the past month". Participants were considered to have changed behaviour if they answered "Yes, agree" or "Yes, strongly agree" to the first question and if they gave an example of change in behaviour that aligned with the evidence-based recommendations - for example, they increased the challenge to balance in exercises prescribed to clients.

\section{Secondary outcome measures}

The three secondary outcomes were:

- Confidence to prescribe fall prevention exercises to people aged 60 years and older, rated on an 11-point Likert scale, anchored at one end with "Most confident" and at the other by "Least confident"

- Proportion of people aged 60 years and older seen in the past month who were prescribed fall prevention exercises. This required participants to determine, from their clinical records, the number of older clients they saw in the past month and, of those, the number who were prescribed fall prevention exercise (expressed as a percentage)

- Proportion of fall prevention exercises prescribed to people aged 60 years and older in the past month that aligned with evidence-based guidelines. Participants listed the specific exercises prescribed, up to a total of six, and the duration and frequency prescribed, as a measure of dose. Fall prevention exercises were defined as being evidence based if they provided a significant challenge to balance (exercise in standing with minimal upper limb support, narrowing of the base of support and movement of the body), and involved a dose of at least 2 hours per week. ${ }^{13}$

Intervention participants also answered open-ended questions at follow-up to explore intervention satisfaction, and motivation to implement knowledge and skills gained.

\section{Statistical analyses}

Analysis of covariance (ANCOVA) on the post-intervention values was used to assess between-group differences (BGDs) in the continuously scored primary outcome (knowledge) and two of the secondary outcomes (confidence, proportion of eligible clients prescribed fall prevention exercise) with $p$ values, mean difference and $95 \%$ confidence interval $(\mathrm{Cl})$. Baseline values and recruitment site were included as covariates.

The difference in the proportion of people reporting a change in exercise prescription behaviour (primary outcome) and proportion of fall prevention exercises prescribed in the past month that complied with evidence-based guidelines, between groups, was assessed using the relative risk (RR) statistic.

For qualitative program evaluation, open-ended responses were analysed thematically ${ }^{15}$ to explore participants' responses to the workshop. Analyses used an intention-to-treat approach and were conducted on de-identified data using SPSS (Chicago: IBM; Version 24) and Stata (College Station, TX: StataCorp LP; Release 14) software packages.

Sample size calculations indicated that a $20 \%$ difference in the proportion of participants reporting a change in exercise prescription behaviour would be detected with a sample size of 220 (control group rate $50 \%$; intervention group rate $70 \%$; alpha $5 \%$; $15 \%$ dropouts). The proportion estimates included in the calculation were based on a previous study of university undergraduates. ${ }^{12}$ This sample would provide $80 \%$ power to detect a $20 \%$ BGD in the proportion of participants who improved on the knowledge test at follow-up (control group rate 50\%; intervention group rate $70 \%$; alpha 5\%; $15 \%$ dropouts). This sample would also be large enough to detect BGDs of $20 \%$ for secondary outcomes.

\section{Ethics}

The trial was registered with the Australian and New Zealand Clinical Trials Registry (number ACTRN12614000224628) and was approved by the Human Research Ethics Committee, University of Sydney, Australia (number 15162). ${ }^{14}$

\section{Results}

Figure 1 shows the flow of participants through the trial. We recruited and randomised 200 health professionals (163 female; 82\%). Recruitment stopped at 20 participants before the original target because of exhausted study funds. Participant follow-up finished in September 2016. 
Follow-up was completed by 176 (88\%) participants. One intervention group participant did not complete follow-up as a result of employment change, and 23 participants (13 intervention, 10 control) were lost to follow-up.

Figure 1. Participant flow

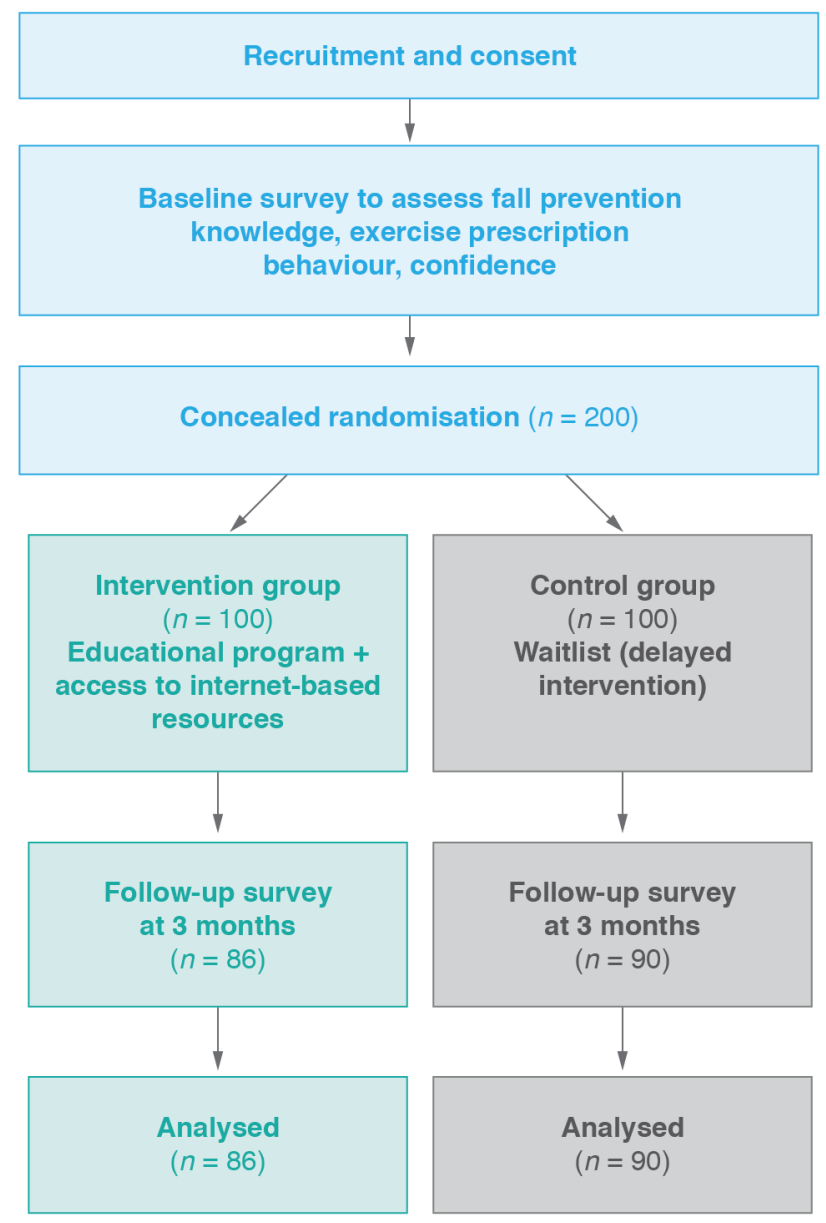

Participants had a range of professional backgrounds, most commonly physiotherapy ( $n=130$; $65 \%$ ), exercise physiology ( $n=23 ; 12 \%$ ), occupational therapy

( $n=20 ; 10 \%)$ and nursing $(n=12 ; 6 \%)$. Participants worked predominantly in hospitals $(n=106 ; 53 \%)$ and community health settings ( $n=35 ; 18 \%)$. Just over half of participants $(52 \%)$ had at least 8 years of experience in their current profession, and most were experienced with prescribing exercise generally (84\%) and fall prevention exercise specifically (79\%). Table 1 summarises the baseline participant demographics and shows that the groups were well matched at baseline.

The education workshop was offered to all 100 intervention group participants, and 93 (93\%) attended. Reasons for non-attendance included illness and inability to get leave from clinical duties. The mean number of days between baseline and follow-up assessments was similar between the intervention and control groups: 126 (standard deviation [SD] 34) and 117 (SD 24) days, respectively.
Comparison of trial outcomes for groups at baseline and follow-up are shown in Table 2. The mean knowledge scores at follow-up were 5.3 (SD 0.9) for the intervention group and 5.0 (SD 0.9) for the control group. There was a small but significant BGD (0.27 points), showing a beneficial effect of the intervention on knowledge.

To assist with interpretation, responses on the 5-point Likert scale indicating change in fall prevention exercise prescription were collapsed and dichotomised into two categories: agreed/strongly agreed behaviour had changed, and unsure/disagreed/strongly disagreed. Sixty-four people in the intervention group (74\%) and $12(13 \%)$ in the control group agreed or strongly agreed that they had changed their fall prevention exercise prescription behaviour, which was a statistically significant difference (see Table 2). The most commonly reported changes were increased focus on balance challenge ( $n=40$ responses) and increasing dose of exercise prescribed to clients ( $n=10$ responses).

Table 1. Characteristics of study participants

\begin{tabular}{|c|c|c|c|}
\hline Characteristic & $\begin{array}{l}\text { Intervention } \\
(n=100)\end{array}$ & $\begin{array}{l}\text { Control } \\
(n=100)\end{array}$ & $\begin{array}{l}\text { Total } n(\%) \\
(n=200)\end{array}$ \\
\hline \multicolumn{4}{|l|}{ Age, years } \\
\hline 20-29 & 35 & 35 & $70(35)$ \\
\hline 30-39 & 24 & 21 & $45(22)$ \\
\hline 40-49 & 14 & 18 & $32(16)$ \\
\hline $50+$ & 27 & 26 & $53(27)$ \\
\hline \multicolumn{4}{|l|}{ Gender } \\
\hline Female & 82 & 81 & $163(82)$ \\
\hline Male & 18 & 19 & 37 (18) \\
\hline \multicolumn{4}{|c|}{ Professional background } \\
\hline Physiotherapist & 67 & 63 & $130(65)$ \\
\hline $\begin{array}{l}\text { Exercise } \\
\text { physiologist }\end{array}$ & 12 & 11 & $23(11.5)$ \\
\hline $\begin{array}{l}\text { Occupational } \\
\text { therapist }\end{array}$ & 9 & 11 & $20(10)$ \\
\hline Nursing & 5 & 7 & $12(6)$ \\
\hline Other & 7 & 8 & $15(7.5)$ \\
\hline \multicolumn{4}{|c|}{ Years in current profession } \\
\hline $0-4$ & 34 & 31 & $65(65)$ \\
\hline $5-7$ & 16 & 15 & $31(31)$ \\
\hline 8-20 & 31 & 28 & $59(59)$ \\
\hline$>20$ & 19 & 26 & $45(45)$ \\
\hline $\begin{array}{l}\text { Experience in } \\
\text { prescribing } \\
\text { fall prevention } \\
\text { exercise }\end{array}$ & 81 & 77 & $158(79)$ \\
\hline $\begin{array}{l}\text { Believe } \\
\text { balance in } \\
\text { older age can } \\
\text { be improved }\end{array}$ & 95 & 99 & $194(97)$ \\
\hline
\end{tabular}


Table 2. Study outcomes for groups at baseline and follow-up, and between-group effects

\begin{tabular}{|c|c|c|c|c|c|}
\hline \multirow[t]{2}{*}{ Variable } & \multicolumn{2}{|c|}{ Baseline } & \multicolumn{2}{|c|}{ Follow-up } & \multirow[t]{2}{*}{ Between-group effects } \\
\hline & $\begin{array}{l}\text { Intervention } \\
(n=100)\end{array}$ & $\begin{array}{c}\text { Control } \\
(n=100)\end{array}$ & $\begin{array}{l}\text { Intervention } \\
\quad(n=86)\end{array}$ & $\begin{array}{l}\text { Control } \\
(n=90)\end{array}$ & \\
\hline $\begin{array}{l}\text { Knowledge score (/6), } \\
\text { score (SD) }\end{array}$ & $5.2(1.0)$ & $5.2(0.8)$ & $5.3(0.9)$ & $5.0(0.9)$ & $\begin{array}{c}\text { Mean } 0.27(95 \% \mathrm{Cl} 0.03 \\
0.51) ; p=0.03\end{array}$ \\
\hline $\begin{array}{l}\text { Knowledge, all correct, } \\
n(\%)\end{array}$ & $42(42)$ & $44(44)$ & $43(50)$ & $27(30)$ & $\begin{array}{c}\text { RR } 1.67(95 \% \mathrm{Cl} 1.1,2.4) \\
p=0.008\end{array}$ \\
\hline $\begin{array}{l}\text { Changed behaviour past } \\
3 \text { months, } n(\%)\end{array}$ & $n / a$ & $n / a$ & $64(74)$ & $12(13)$ & $\begin{array}{l}\text { RR } 5.58 \text { (95\% Cl } 3.25 \\
\text { 9.59); } p<0.0001\end{array}$ \\
\hline $\begin{array}{l}\text { Confidence (/10), score } \\
\text { (SD) }\end{array}$ & $6.8(2.1)$ & $6.9(2.2)$ & $8.1(1.5)$ & $7.0(2.3)$ & $\begin{array}{c}\text { Mean } 1.02(95 \% \mathrm{Cl} 0.65, \\
1.39) ; p<0.001\end{array}$ \\
\hline $\begin{array}{l}\text { Percentage of clients } \\
\text { prescribed fall prevention } \\
\text { exercise, mean (SD) }\end{array}$ & $46.8(38.8)$ & $46.1(36.7)^{b}$ & $53.7(35.1)$ & $52.2(36.2)$ & $\begin{array}{c}\text { Mean } 1.7(95 \% \mathrm{Cl}-7.11 \\
10.43) ; p=0.7\end{array}$ \\
\hline $\begin{array}{l}\text { Evidence-based exercises } \\
\text { prescribed (/6), number } \\
(\mathrm{SD})^{\mathrm{a}}\end{array}$ & $4.9(1.2)$ & $5.1(1.2)$ & $5.3(1.1)$ & $5.1(1.2)$ & $\begin{array}{c}\text { Mean } 0.36(95 \% \mathrm{Cl} 0.03 \\
0.68) ; p=0.03\end{array}$ \\
\hline $\begin{array}{l}\text { Dose prescribed, minutes/ } \\
\text { week (SD) }\end{array}$ & $98.4(62.3)$ & $118.2(70.1)$ & $130.2(74.8)$ & $114.5(64.0)$ & $\begin{array}{c}\text { Mean } 21.59(95 \% \mathrm{Cl}-2.14 \\
45.32) ; p=0.07\end{array}$ \\
\hline $\begin{array}{l}\text { Dose } \geq 2 \text { hours/week, } n \\
(\%)^{c}\end{array}$ & $30(39)$ & $36(46)$ & $44(60)$ & $28(39)$ & $\begin{array}{l}\text { RR } 1.53(95 \% \text { Cl } 1.08 \\
2.15) ; p=0.015\end{array}$ \\
\hline
\end{tabular}

$\mathrm{Cl}=$ confidence interval; $\mathrm{n} / \mathrm{a}=$ not applicable; $\mathrm{RR}=$ relative risk; $\mathrm{SD}=$ standard deviation

a Between-group differences from analysis of covariance models, including baseline values and recruitment site as covariates

b $n=96$ due to missing data

Responses only from people who prescribed fall prevention exercise in the past month

The mean rating of confidence to prescribe fall prevention exercises (out of 10) at follow-up was higher in the intervention group (mean 8.1; SD 1.5) than in the control group (mean 7.0; SD 2.3). There was a significant BGD of 1.02 points, showing a beneficial effect of the intervention on confidence.

At follow-up, 74 (86\%) intervention participants and $72(80 \%)$ control participants reported prescribing fall prevention exercise in the past month. The mean number of clients prescribed fall prevention exercise as a proportion of total clients seen in the month before follow-up, expressed as a percentage, was similar in the intervention group (53.7\%; SD 35.1) and the control group (52.2\%; SD 36.2). The BGD (1.7\%) was not significant.

At follow-up, the mean number of evidence-based fall prevention exercises prescribed (out of a possible total of 6) in the intervention group was 5.3 (SD 1.1) and in the control group was 5.1 (SD 1.2). This represented a small but statistically significant BGD of 0.36 .

The dose of exercise prescribed by intervention participants at follow-up (130 minutes/week; SD 75) was higher than that prescribed by control participants (115 minutes/week; SD 64). However, the BGD of 22 minutes/week did not reach statistical significance. As well, the percentage of participants who prescribed at least 2 hours/week of fall prevention exercise was significantly higher in the intervention group than in the control group at follow-up (60\% versus 39\%).

We also conducted an unplanned analysis of the proportion of people who answered every knowledge question correctly at follow-up. Of the intervention participants, 43 (50\%) correctly answered all six questions, compared with 27 (30\%) of control participants, and this difference was statistically significant.

Overall, intervention participants enjoyed the workshop format, found the practical components useful and liked the sharing of ideas between participants. For example, one participant commented that "the practical sessions were great - especially case studies and having the assessment equipment available to trial"; another said they found "talking through progression and regression of balance exercises was very useful". At follow-up, 60 intervention participants $(70 \%)$ reported accessing the internet-based resources, and 82 participants (95\%) said that they would recommend the workshop to others. 


\section{Discussion}

A 1-day workshop about exercise for fall prevention significantly improved knowledge, confidence and exercise prescription behaviour among health and exercise professionals. The positive response to the face-to-face workshop format supports inclusion of this type of education program for health professionals as a core component of training or ongoing professional development.

The intervention improved exercise prescription behaviour, with participants citing a greater emphasis on prescribing balance-challenging exercise to older clients, and increasing exercise dose. This is an important finding, since evidence from systematic reviews ${ }^{2}$ identifies these two factors as being crucial for fall prevention.

The intervention impact on knowledge was small, probably as a result of the high level of baseline knowledge across all participants. Although statistically significant, the BGD at follow-up resulted from a decrease in control group knowledge and a slight increase in knowledge by the intervention group. A more challenging measure of knowledge may have provided a better indication of the intervention impact.

There was a large positive intervention effect on the secondary outcomes of participants' confidence to prescribe fall prevention exercise and the type of exercise prescribed. This impact on confidence is important since a previous review identified lack of self-efficacy as a barrier to clinical guideline implementation by health professionals. ${ }^{16}$

The intervention was not associated with a change in the proportion of older clients prescribed fall prevention exercises. This may reflect the constrained systems within which health and exercise professionals often work - these systems may lack the flexibility to allow health professionals to promote fall prevention strategies when focusing on other health complaints. ${ }^{17}$ As well, funding models may dictate the types of services that can be provided. Greater awareness of the risk of falls in older age and the role of exercise in preventing falls may increase the scope for implementing fall prevention strategies in a variety of settings.

Importantly, in addition to the demonstrated impact on the trial outcomes, the education program was well received by the participants, and most indicated that they would recommend it to others. Use of combined interactive and didactic teaching approaches, as in this study, has previously been associated with a greater effect on professional practice than other approaches. ${ }^{3}$ Previous research has also suggested that educational strategies may be less effective if they target outcomes that are perceived to have less serious consequences for patients. ${ }^{3}$ This emphasises the importance of including detailed, evidence-based context for any health condition being targeted, as we did in our workshop.

\section{Strengths and limitations}

A key strength of this trial is its detailed, prospectively registered protocol, following CONSORT guidelines. We minimised bias by using concealed random allocation, intention-to-treat analysis and planned statistical analyses.

We acknowledge certain limitations, including use of self-reported outcome measures, leading to risk of recall and response bias. Participants started the trial with a high level of fall prevention knowledge, and many were already providing fall prevention services. Further strategies may be needed to promote knowledge uptake and behaviour change in health and exercise professionals who are naive to fall prevention services.

Since more than $80 \%$ of participants were female, the intervention impact on male health and exercise professionals is less certain. As well, most trial participants (65\%) had a professional background in physiotherapy, reducing the certainty about intervention impact for other professions. Further research is required to test the intervention impact when delivered to health professionals with varying levels of baseline experience and knowledge.

\section{Conclusion}

Our trial demonstrates the positive impact of an education workshop on fall prevention for health and exercise professionals, and supports the implementation of such educational activities more broadly. Further research is required to determine whether a more skilled and confident allied health and exercise workforce results in a measurable reduction in fall incidence among communitydwelling older people.

\section{Acknowledgements}

This work is supported by a National Health and Medical Research Council (NHMRC) Partnerships for Better Health Grant (ID: 1016876). Authors AT, CS and SL receive salary funding through NHMRC fellowships. This funder had no role in the study design, execution, analyses or interpretation, or the decision to submit results.

AT has received payment from the NSW Falls Prevention Network for delivery of education workshops, and DS has receved payment from the NHMRC study grant for delivering workshops. SL has received royalties from Cambridge United Press for a monograph on falls.

\section{Peer review and provenance}

Externally peer reviewed, not commissioned.

\section{Competing interests}

None declared. 


\section{Author contributions}

CS, AT, SL and LC conceived the study. AT, CS, A-MH, LL and SL initiated the study design, and DS assisted implementation. AT conducted the primary statistical analysis. All authors approved the final manuscript.

\section{References}

1. Lord SR, Ward JA, Williams P, Anstey KJ. An epidemiological study of falls in older community-dwelling women: the Randwick falls and fractures study. Australian J Pub Health. 1993;17:240-5.

2. Sherrington C, Michaleff ZA, Fairhall N, Paul SS, Tiedemann A, Whitney $\mathrm{J}$, et al. Exercise to prevent falls in older adults: an updated systematic review and metaanalysis. Brit J Sport Med. 2017;51:1750-58.

3. Forsetlund L, Bjorndal A, Rashidian A, Jamtvedt G, O'Brien MA, Wolf $F$, et al. Continuing education meetings and workshops: effects on professional practice and health care outcomes. Cochrane Database Syst Rev. 2009;(2):CD003030.

4. O'Brien MA, Rogers S, Jamtvedt G, Oxman AD, Odgaard-Jensen J, Kristoffersen DT, et al. Educational outreach visits: effects on professional practice and health care outcomes. Cochrane Database Syst Rev. 2007(4):CD000409.

5. Jamtvedt G, Young J, Kristoffersen DT, O'Brien MA, Oxman AD. Audit and feedback: effects on professional practice and health care outcomes. Cochrane Database Syst Rev. 2006;(2):CD000259.

6. Thomas L CN, McColl E, Rousseau N, Soutter J, Steen N. Guidelines in professions allied to medicine. Cochrane Database Syst Rev. 2000;(2):CD000349.

7. van der Wees PJ, Jamtvedt G, Rebbeck T, de Bie RA, Dekker J, Hendriks EJM. Multifaceted strategies may increase implementation of physiotherapy clinical guidelines: a systematic review. Aust J Physiother. 2008;54:233-41.

8. Renders CM, Valk GD, Griffin S, Wagner EH, Eijk JT, Assendelft WJ. Interventions to improve the management of diabetes mellitus in primary care, outpatient and community settings. Cochrane Database Syst Rev. 2001;2000(1):CD001481.
9. Moralejo D, El Dib R, Prata RA, Barretti P, Corrêa I. Improving adherence to standard precautions for the control of health care-associated infections. Cochrane Database Syst Rev. 2018;2(2):CD010768.

10. Pit SW, Byles JE, Henry DA, Holt L, Hansen V, Bowman DA. A quality use of medicines program for general practitioners and older people: a cluster randomised controlled trial. Med J Aust. 2007;187:23-30.

11. Sherrington C, Fairhall NJ, Wallbank GK, Tiedemann A, Michaleff ZA, Howard K, et al. Exercise for preventing falls in older people living in the community. Cochrane Database Syst Rev. 2019;1(1):CD012424.

12. Pascoe DA, Sturnieks DL, Close JCT, Tiedemann A, Lord S, Twomey D, Finch CF. Knowledge outcomes and retention of a university-based falls prevention education program. Focus on Health Professional Education. 2013;15:55-66.

13. Sherrington C, Tiedemann A, Fairhall N, Close JCT, Lord SR. Exercise to prevent falls in older adults: an updated meta-analysis and best practice recommendations. NSW Public Health Bull. 2011;22:7883.

14. Tiedemann A, Sturnieks DL, Hill A-M, Lovitt L, Clemson L, Lord SR, et al. Does a fall prevention educational programme improve knowledge and change exercise prescribing behaviour in health and exercise professionals? A study protocol for a randomised controlled trial. BMJ Open. 2014;4(11):e007032.

15. Braun V, Clarke V. Using thematic analysis in psychology. Qual Res Psych. 2006;3:77-101.

16. Fischer F, Lange K, Klose K, Greiner W, Kraemer A. Barriers and strategies in guideline implementation - a scoping review. Healthcare (Basel). 2016;4:36.

17. Liddle J, Lovarini M, Clemson L, Mackenzie L, Tan A, Pit SW, et al. Making fall prevention routine in primary care practice: perspectives of allied health professionals. BMC Health Serv Res. 2018;18:598.

\section{Copyright: (cc)}

(C) 2020 Tiedemann et al. This article is licensed under the Creative Commons Attribution-NonCommercial-ShareAlike 4.0 International Licence, which allows others to redistribute, adapt and share this work non-commercially provided they attribute the work and any adapted version of it is distributed under the same Creative Commons licence terms. See: www.creativecommons.org/licenses/by-nc-sa/4.0/ 